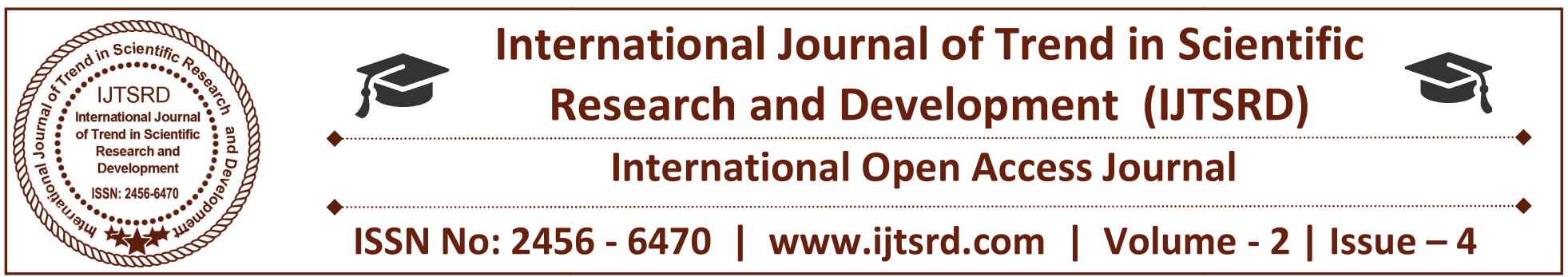

\title{
Study of Mechanical Properties of Banana and E-Glass Fiber Composite
}

\author{
Yegireddy Haribabu \\ Assistant Professor, Mechanical Engineering, \\ Aditya Institute of Technology and Management, Andhra Pradesh, India
}

\begin{abstract}
The purpose of this research work is evaluated and compares the mechanical properties of laminates prepared of different components of banana and Eglass fibers. The mechanical properties evaluated are tensile strength flexural strength, impact strength. The four laminates of banana and E-glass fibers of dimensions $150 * 150 * 5 \mathrm{~mm}^{\wedge} 3$ is fabricated by using by hand layup method.

From the results of the testing process, it is found that the maximum tensile strength, maximum flexural strength and maximum impact strength is observed in pure E-glass fiber laminate and minimum in pure banana fiber laminate. From the entire test, it is found that as the glass layer in the laminate increases its mechanical properties enhances.
\end{abstract}

Keywords: Banana fiber, E-glass fiber, |polyester, Mechanical properties.

\section{INTRODUCTION}

A composite is combination of two materials in which one of the materials, called the reinforcing phase, is in the form of fibers, sheets, or particles, and is embedded in the other materials called the matrix phase. The reinforcing material and the matrix material can be metal, ceramic, or polymer. Composites typically have a fiber or particle phase that is stiffer and stronger than the continuous matrix phase and serve as the principal load carrying members. The matrix acts as a load transfer medium between fibers, and in less ideal cases where the loads are complex, the matrix may even have to bear loads transverse to the fiber axis. The matrix is more ductile than the fibers and thus acts as a source of composite toughness. The matrix also serves to protect the fibers from environmental damage before, during and after composite processing. When designed properly, the new combined material exhibits better strength than would each individual material. Composites are used not only for their structural properties, but also for electrical, thermal, tribological, and environmental applications.

According to type of matrix material they are classified as:

1. Metal Matrix Composites (MMC)

2. Ceramic Matrix Composites (CMC)

3. Polymer Matrix Composites (PMC)

Matrix Composites:

Higher strength, fracture toughness and stiffness are offered by metal matrices. Metal matrix can withstand elevated temperature in corrosive environment than polymer composites. Titanium, aluminum and magnesium are the popular matrix metals currently in vogue, which are particularly useful for aircraft applications. Because of these attributes metal matrix composites are under consideration for wide range of applications viz. combustion chamber nozzle (in rocket, space shuttle), housings, tubing, cables, heat exchangers, structural members etc

\section{Polymer Matrix Composites:}

Most commonly used matrix materials are polymeric. In general the mechanical properties of polymers are inadequate for many structural purposes. In particular their strength and stiffness are low compared to metals and ceramics. These difficulties are overcome by reinforcing other materials with polymers. Secondly the processing of polymer matrix composites need not involve high pressure and 
doesn't require high temperature. Also equipments required for manufacturing polymer matrix composites are simpler. For this reason polymer matrix composites developed rapidly and soon became popular for structural applications.

\section{NATURAL \\ FIBER COMPOSITES \\ REINFORCED}

The interest in natural fiber-reinforced polymer composite materials is rapidly growing both in terms of their industrial applications and fundamental research. They are renewable, cheap, completely or partially recyclable, and biodegradable. Plants, such as flax, cotton, hemp, jute, sisal, kenaf, banana pineapple, ramie, bamboo, banana, etc., as well as wood, used from time immemorial as a source of lignocelluloses fibers, are more and more often applied as the reinforcement of composites. Their availability, renewability, low density, and price as well as satisfactory mechanical properties make them an attractive ecological alternative to glass, carbon and man-made fibers used for the manufacturing of composites. The natural fiber-containing composites are more environmentally friendly, and are used in transportation (automobiles, railway coaches, aerospace), military applications, building / and construction industries (ceiling paneling, partition boards), packaging, consumer products.

\section{LITERATURE REVIEW}

Jartiz [1] stated that "Composites are multifunctional material systems that provide characteristics not obtainable from any discrete material. They are cohesive structures made by physically combining two or more compatible materials, different in composition and characteristics and sometimes in form".

Kelly [2] very clearly stresses that the composites should not be regarded simple as a combination of two materials. In the broader significance; the combination has its own distinctive properties. In terms of strength to resistance to heat or some other desirable quality, it is better than either of the components alone or radically different from either of them.

Beghezan [3] Defines as "The composites are compound materials which differ from alloys by the fact that the individual components retain their characteristics but are so incorporated into the composite as to take advantage only of their attributes and not of their short comings", in order to obtain improved materials.

Van Suchetclan [4] explains composite materials as heterogeneous materials consisting of two or more solid phases, which are in intimate contact with each other on a microscopic scale. They can be also considered as homogeneous materials on a microscopic scale in the sense that any portion of it will have the same physical property.

The following are some of the reasons why composites are selected for certain applications:

$>$ High strength to weight ratio (low density high tensile strength)

High creep resistance

High tensile strength at elevated temperatures High toughness

\section{MATERILAS AND METHODS}

The composite laminates for this work were fabricated by hand lay-up process. Hand lay-up is the simplest and low cost manufacturing method suitable for academic purposes/low volume production. Initially the banana fibers are dried under the hot sun to remove the moisture for more than 24 hours. In order to orientate the fiber in the composite material, the dried banana fibers are to be woven. The method for weaving the banana fiber for making a specimen is well detailed. The woven fiber mats of thickness were pre-pared from banana fibers of particular length. Four different kinds of laminates were prepared with stacking sequences.

\section{B/B/B (Laminate 1)}
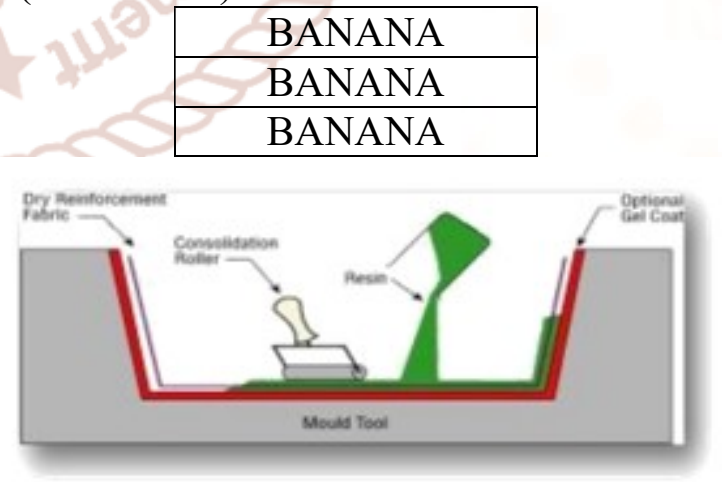

$\mathrm{G} / \mathrm{G} / \mathrm{G}$ (Laminate 2)

\begin{tabular}{|l|}
\hline E GLASS \\
\hline E GLASS \\
\hline E GLASS \\
\hline
\end{tabular}

G/B/G/ (Laminate 3).

E GLASS 
International Journal of Trend in Scientific Research and Development (IJTSRD) ISSN: 2456-6470

$\mathrm{B} / \mathrm{G} / \mathrm{B}$ (Laminate 4)

\begin{tabular}{|c|}
\hline BANANA \\
\hline E GLASS \\
\hline
\end{tabular}

\begin{tabular}{|c|}
\hline BANANA \\
\hline E GLASS \\
\hline BANANA \\
\hline
\end{tabular}

\section{CALCULATION:}

For the preparation of the composite we calculate the percentage of fibers, polymer and hardener required from the table we come to know about the amounts accurately.

\begin{tabular}{|l|l|l|l|}
\hline S No & BANANA & E GLASS & EPOXY \\
\hline 1 & $30 \%$ & & $70 \%$ \\
\hline 2 & & $30 \%$ & $70 \%$ \\
\hline 3 & $10 \%$ & $20 \%$ & $70 \%$ \\
\hline 4 & $20 \%$ & $10 \%$ & $70 \%$ \\
\hline
\end{tabular}

First of all mould release spray was spread overall after that we pour some mixture after that we place one banana mate. Above that we pour mixture of fiber polymer mixture. Again we place another banana mate then above that pour some polymer mixture. Again we place another banana mate then above that pour some polymer This sample is then left for 72 hours. The composite gets dried up in 72 hours in which the silk fiber and the polymers adheres itself tightly in the presence of hardener. After a day we put out the weights. Then carefully the nailed bits are removed from the wooden board. Now we have the composite attached with the glass. The hardener has so strong effect that it attachés the glass with the composite. This attachment is slowly and gently hammered on the boundary of its attachment when the glass and the composite separate out. Then we see whether any undesired voids are left behind. We fill the voids with polymer and the sample is prepared.

\section{EXPERIMENT PROCEDURE}

\section{CUTTING OF LAMINATES INTO SAMPLES OF DESIRED DIMENSIONS:}

A WIRE HACKSAW blade was used to cut each laminate into smaller pieces, for various experiments:

TENSILE TEST- Sample was cut into dog bone shape (150x19x7)mm.

FLEXURAL TEST- Sample was cut into flat shape $(90 \times 10 \times 5) \mathrm{mm}$, in accordance with ASTM standards.
CHARPY TEST - Sample was cut into flat shape (55 $\mathrm{x} 10 \times 5) \mathrm{mm}$ in accordance with ASTM standards

\section{TENSILE TEST}

\begin{tabular}{|c|c|c|c|c|}
\hline $\begin{array}{l}\text { Speci } \\
\text { men }\end{array}$ & $\begin{array}{l}\text { Break } \\
\text { load } \\
(\mathrm{KN})\end{array}$ & $\begin{array}{c}\text { Tensilestren } \\
\text { gth } \\
\left(\mathrm{KN} / \mathrm{mm}^{\wedge} 2\right)\end{array}$ & $\begin{array}{c}\text { YSIU } \\
\text { TS } \\
\text { (Ratio }\end{array}$ & UTS \\
\hline L1 & 0.870 & 0.016 & 0.678 & 141.02 \\
\hline L2 & 5.420 & 0.136 & 0.078 & 16.22 \\
\hline L3 & 2.460 & 0.044 & 0.240 & 45 \\
\hline L4 & 1.82 & 0.012 & 0.47 & 23 \\
\hline
\end{tabular}
accordance with ASTM standard. All the specimens were of dog bone shape of dimension $(150 \times 8 \times 5) \mathrm{mm}$.

\section{IMPACT TEST}

Impact Property The loss of energy during impact is the energy absorbed by the specimen during impact. The values are tabulated in Table shows a comparison between energy absorbed by the different combination of composites. The L2 shows very high impact strength compare to all other laminates, The L1 shows very poor impact strength of 2
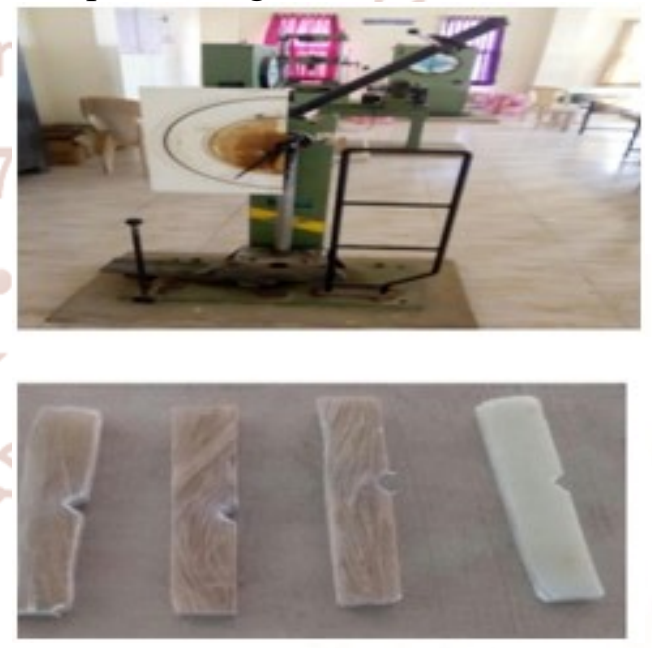

\begin{tabular}{|c|c|}
\hline Specimen & Impact strength (i) \\
\hline L 1 & 2 \\
\hline L 2 & 10 \\
\hline L 3 & 6 \\
\hline L 4 & 4 \\
\hline
\end{tabular}




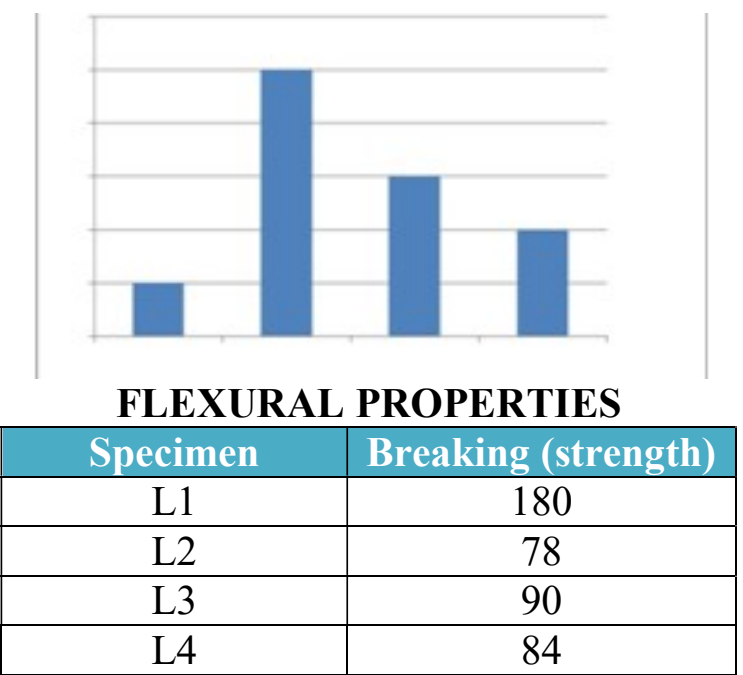

The flexural properties including flexural modulus and ultimate flexural strength(UFS) of composites L1, L2, L3 and L4 are tabulated in Table. Typical load vs.Length curves are shown in figure. The Laminate L1 shows a high flexural strength of 180 $\mathrm{N} / \mathrm{mm} 2$ and L2 which shows a lower flexural strength of $78 \mathrm{~N} / \mathrm{mm} 2$.

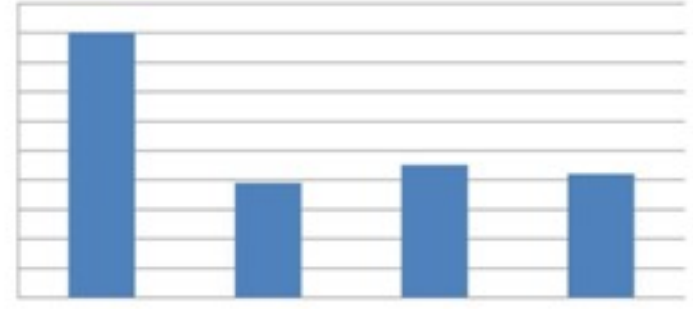

\section{CONCLUSION}

1. This project presents the fabrication of hybrid composite using banana and E-glass fiber reinforced polymer composite by hand layup method. From the tests The following conclusion are drawnSince the laminates are cured using hand layup method is very simple and less cost..

2. From the tensile test it is found that, the maximum tensile strength was pure E-glass layer and minimum is pure banana.

3. Flexural test result shown that, laminates. L1 (180Mpa) has the highest flexural strength and L 2 (78Mpa) has the lowest flexural strength
4. It is found from the impact test that, impact strength of laminate $\mathrm{L} 2$ is the highest $(10 \mathrm{~J})$ and $\mathrm{L}$ $1(2 \mathrm{j})$ has the lowest impact strength

\section{REFERNECE}

1. Sanjay M. R., Arpitha G. R., Yogesha B., Mater. Today: Procee. 2 (2015) 2967.

2. Avinash R. Pai., Ramanand N. Jagtap., J. Mater. Environ. Sci. 6(4) (2015) 917.

3. Arpitha G.R., Sanjay M.R., Yogesha B., Adv. Engg. Appd. Sci: An Inter. J. 4(4) (2014) 47.

4. Alexandre Gomes., Takanori Matsuo., Koichi Goda., JunjiOhgi., Compo: Part A.(2007) 1820.

5. Velmurugan R., Manikandan V., Compo: Part A. 38 (2007) 2216-2226.

6. Davoodi M. M., Sapuan S. M., Ahmad D., Aidy Ali, Khalina A., Mehdi Jonoobi, Mater. Design. 31 (2010) 4932.

7. Ramanaiah K., Ratna Prasad A. V., Hema Chandra Reddy K., J. Mater. Environ. Sci. 3 (3) (2012) 378.

8. Leonard Y. Mwaikambo., Elias T. N. Bisanda., Poly. Test. 18 (1999) 198.

9. Sreekala M. S., Jayamol George., Kumaran M. G., Sabu Thomas., Compo. Sci. Tech. 62 (2002) 353

10. Mishra S., Mohanty A. K., Drzal L. T., Misra M., Parija S., Nayak S. K., Tripathy S. S., Compo. Sci. Tech. 63 (2003) 1385.

11. Paul Wambua., Jan Ivens., IgnaasVerpoest., Compo. Sci. Tech. 63 (2003) 1264.

12. Yongli Zhang., Yan Li., Hao Ma., Tao Yu., Compo. Sci. Tech. 88 (2013) 177.

13. Boopalan M., Niranjanaa M., Umapathy M.J., $\begin{array}{lllll}\text { Compo: } & \text { Part } & \text { B. } & 51 & \text { (2013) }\end{array}$ 